\section{Transition to a steady state of repeated acquisition*}

\author{
DONALD M. THOMPSON \\ Department of Pharmacology \\ Georgetown University Schools of Medicine and Dentistry \\ Washington, D.C. 20007
}

Pigeons obtained food reinforcement via a four-response chain that required pecking different keys in the presence of different colors. The sequence of correct key positions changed from session to session. Errors gradually decreased across sessions until a constant minimum range of variability in error levels was reached (steady state). Other characteristics of the transition and steady state of repeated acquisition (e.g., within-session rate of error reduction) were described.

Thompson (1970) reported a technique for studying variables affecting acquisition using an individual-S design. Briefly, the situation was as follows: each $S$ (pigeon) worked for food reinforcement in a chamber containing three response keys, which could be transilluminated with any one of four colors. For each session, the pigeon's task was to learn a new four-response chain by pecking the correct key in each group of colors. Eventually, the rate of learning (error reduction) stabilized from session to session. A general discussion of the rationale and methodology involved in the study of transition and steady states can be found in Sidman (1960).

The purpose of the present report is to describe the transition to the steady state ("learning to learn") obtained in the Thompson (1970) experiment and to provide further details about the characteristics of the steady state itself. Boren (1963) used a similar approach and technique with monkeys to produce a steady state of repeated acquisition. However, Boren's focus was on the steady state as a behavioral baseline to study the effects of time-out and "instructional" stimuli (Boren, 1963; Boren \& Devine, 1968) and adventitious reinforcement (Boren, 1969) rather than on the transition to this steady state.

$$
\text { SUBJECTS }
$$

The Ss were two 5-year-old male experimentally naive White Carneaux pigeons. They were maintained at $80 \%$ of free-feeding weight. Water was always available in the home cages.

\section{APPARATUS}

The apparatus was a standard three-key pigeon chamber (LVE Model 1519B) and connecting automatic control equipment. The scheduling of events was accomplished by means of timers, steppers, and

* This research was supported in part by Public Health Service Grants FR 5360 and FR 5306 .

associated relay circuitry; the recording was by counters and a 20-pen event recorder. White noise was continuously present in the chamber to mask extraneous sounds.

\section{PROCEDURE}

Throughout the following procedures, the primary reinforcer was food (5-sec access to mixed grain). Presentation of the food magazine was accompanied by the offset of the keylights, the offset of the houselight (which was on only during magazine training and shaping), and the onset of the magazine light. Each session terminated after 60 food presentations. A "blackout" (all lights off) of variable duration preceded and followed each session. With few exceptions, there were six daily sessions a week.

Preliminary Training

Preliminary training included magazine training, shaping of key pecking, and reinforcing pecks on each of the three keys, which were transilluminated with white lights. The birds were then trained to make a

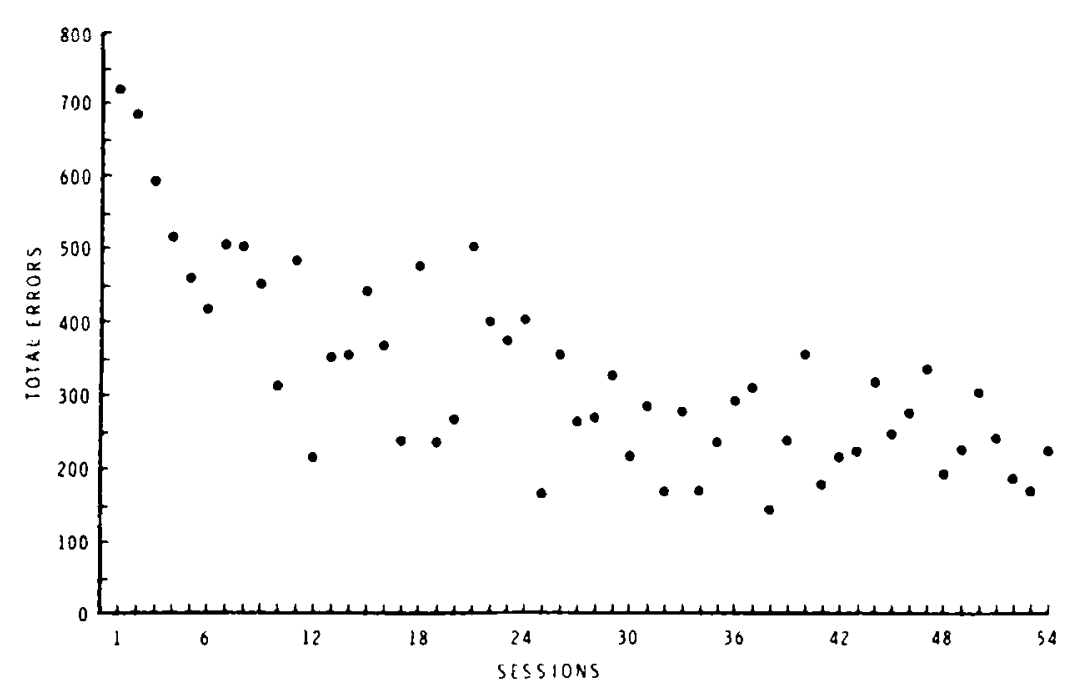

Fig. 1. Total errors across sessions for one S. The chained sequence of correct

key positions was changed from session to session.

chain of responses. At first, food presentation was contingent upon a chain of two responses. The three keys were transilluminated with red lights, and a peck on any key changed the lights to white. Then, when the bird pecked any of the white keys, it received food, after which the red keylights reappeared, etc. In the same way, the chain was extended gradually to include the two other colors. Thus, the bird pecked the keys four times, once in the presence of the yellow, green, red, and white lights, with the final peck followed by access to grain. This preliminary training required four sessions.

The fifth session was the first baseline session. Only responses on specified keys in the presence of each set of colors led to food presentation, e.g., keys yellow-left correct; keys green-right correct; keys red-center correct; keys white-right correct; food. The same sequence (LRCR) was repeated throughout the session. When the pigeon pecked an incorrect key (a key not included in the above sequence), the error was followed by a 15-sec time-out. During the time-out, the keylights were off and a response had no effect. An error did not reset the sequence, i.e., the keylights after the time-out were the same color as before the time-out. For convenience, each completion of the sequence was considered a "trial," even though there was no "intertrial interval" as conventionally defined. The errors made during a trial were recorded separately for each color, and their reduction during a 60-trial session was taken as an index of the rate of learning.

The sequence of correct key positions was changed from session to 


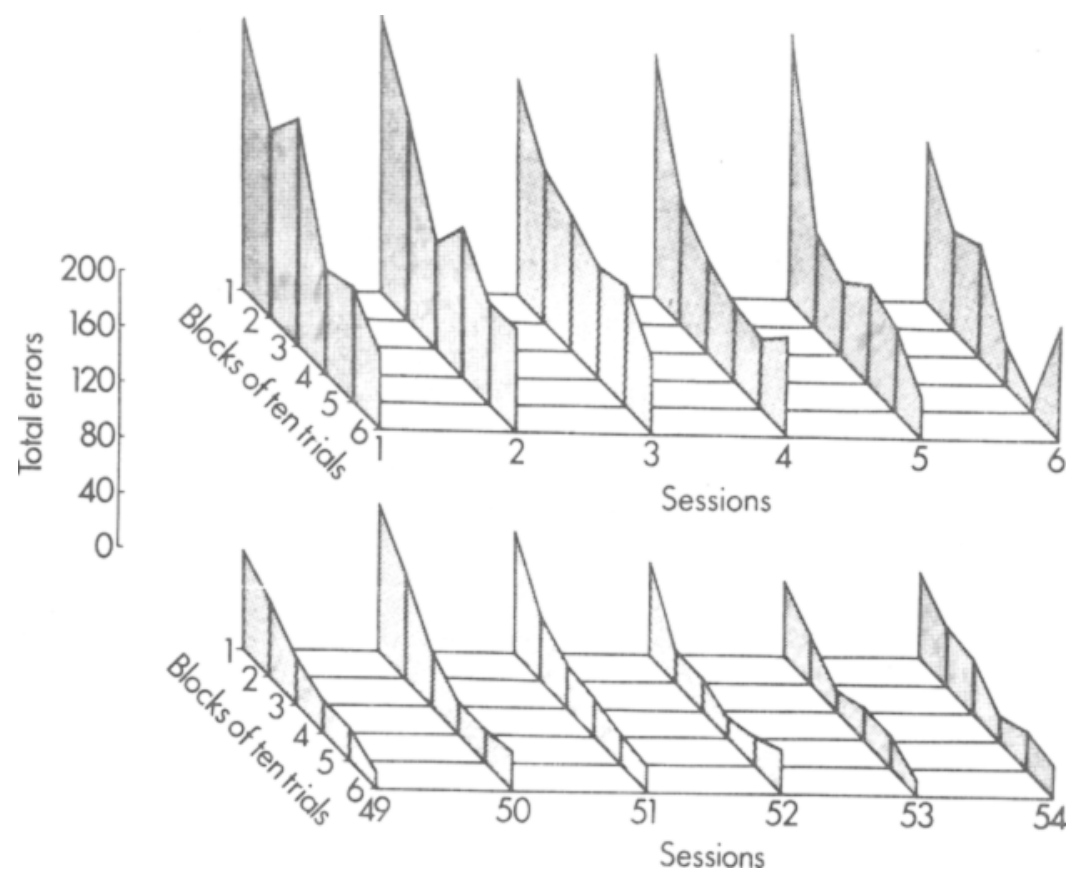

Fig. 2. Total errors across trials within selected sessions from Fig. 1. The chained sequence of correct key positions was the same from trial to trial within a given session.

session. Following Boren, the sequences were carefully selected to be equivalent in several ways, and there were restrictions on their ordering across sessions. First, a correct color position in one session was not repeated in the following session. Second, simple orders, such as the left key in each group of colors, were avoided. In the present research, adjacent positions in each sequence were always different, although each position occurred at least once. Third, within a set of six sequences, each key position appeared equally often (twice) in each color. An example of a typical set of six sequences is as follows: LRCR, CLRL, LRLC, RCRL, CLCR, RCLC. The order of the associated colors was always the same: yellow, green, red, white (food).

RESULTS AND DISCUSSION

Figure 1 shows the transition to the steady state of repeated acquisition for one $S$ in terms of total errors per baseline session. As can be seen, there was a definite downward trend in error levels as the sessions continued, with the sharpest drop occurring during the first set of six sessions. The variability in error levels also appeared to decrease across sessions until a minimum range of variability was obtained (steady state). During the last 30 baseline days (Sessions 25-54), almost all of the data points fell within the range of $150-350$ errors. Experimentation after Session 54 (Thompson, 1970) and subsequent research have indicated that the total errors per baseline session remain within this range indefinitely for this S.

In general, the variability in total errors did not seem to be related to the specific chained sequences employed. However, there were two exceptions worth noting: (1) Any sequence in which the correct key positions required LCR or $\mathrm{RCL}$ responding tended to be easier to learn than the others. For example, Sessions 32 (RLCR), 34 (LCRL), 38 (CLCR), 41 (RCLC), 48 (CRCL), 52 (LCRL), and 53 (RLCR) were all associated with relatively low error levels (Fig. 1). (2) Although the ordering of sequences across sessions was restricted so that a particular sequence for one session would not be repeated in the following session, there was one occasion during the first 54 baseline sessions in which a sequence was repeated after only one intervening session involving a different sequence. Sessions 23 and 25 both involved the same sequence (LCLR), and this probably accounts for the relatively low level of errors during Session 25 (Fig. 1). The error levels were not unusual if two or more sessions with different sequences intervened between sessions with the same sequence. Both of the above observations have been confirmed repeatedly by subsequent research.

Figure 2 shows the within-session learning curves for the first and last set of six sessions under the baseline conditions for the $\mathrm{S}$ whose total errors per session were shown in Fig. 1. As can be seen, the learning curves for the first six sessions were quite variable when compared to the last six sessions of baseline. The relatively narrow range of variability between learning curves for Sessions 49-54 was subsequently maintained for this $\mathrm{S}$ as long as the baseline conditions were in effect. It should be noted that although the errors showed a systematic decrease during each session, the lowest level of errors was still somewhat above zero (cf. Boren \& Devine, 1968). However, there was no evidence that these errors represented "superstitious" responses within the reinforced chain (cf. Boren, 1969).

Taken together, the transition data in Figs. 1 and 2 can be considered to illustrate two types of learning: (1) learning within each session, as shown by the systematic decrease in errors across trials, and (2) "learning to learn" or "learning set formation" (Harlow, 1949; Zeigler, 1961), as shown by the gradual decrease in total errors across sessions. Presumably, the within-session transition involved learning to respond to a specific key position (left, center, or right), depending on the presence of a specific color (yellow, green, red, or white). That the different colors were, in fact, controlling the behavior in this "conditional discrimination" has been demonstrated (Thompson, 1970). The between-session transition may have involved learning more subtle "rules for reinforcement" (Goldiamond, 1966) such as the restriction that the position of the correct key always changed when the chained sequence advanced a step to the next color. In short, this "win-switch" rule could have been learned through the repeated acquisition of the different behavioral chains. Of course, the "learning to learn" could have involved the other restrictions made on the ordering of the sequences of correct key positions across sessions (see Procedure) or still other variables. However, the present research was not designed to isolate the basis for such learning.

An inspection of the distribution of errors across the four serial positions in the chained sequences for the transition and steady-state sessions revealed no discernible pattern or gradient. In general, there was great variability in the error distributions throughout these sessions, even after the baseline had stabilized in terms of learning curves (Fig. 2). Subsequent experimentation involving over 200 baseline sessions has suggested that such variability persists indefinitely. Boren (personal communication) has made the same observation with monkeys under similar conditions. 
Although the measures involving errors were the data of major interest in the present research, there were other characteristics of the transition and steady state that should be mentioned. With regard to the total time required to complete the 60 trials of each session shown in Fig. 1, this varied from almost $8 \mathrm{~h}$ for the first session to about $1 \mathrm{~h}$ for the last session; the range for the last set of six sessions (55-95 $\mathrm{min})$ is representative of the steady-state session times. Of course, a substantial part of the session time was the time spent in the 15-sec time-outs that resulted from incorrect responses. Considering only the total trial time (i.e., the total time that the keylights were on during a session), this varied from almost $320 \mathrm{~min}$ for the first session to about $10 \mathrm{~min}$ for the last session; the range for the last set of six sessions $(8-13 \mathrm{~min})$ is representative of the steady-state total trial times. A final characteristic of the transition and steady state was the negligible amount of responding during time-out. Such responding ranged from 0 to 5 throughout each session shown in Fig. 1.

In general, all of the comparative aspects of the transition and steady state mentioned above were replicated with the other $S$, the only important difference being that the minimum ranges of variability (errors, session times, trial times, etc.) were somewhat greater for the second $\mathrm{S}$.

\section{REFERENCES}

BOREN, J. J. Repeated acquisition of new behavioral chains. American Psychologist. 1963, 17, 421 (A bstract).

BOREN, J. J. Some variables affecting the superstitious chaining of responses. Journal of the Experimental Analysis of Behavior, 1969, 12, 959-969.

BOREN, J. J. \& DEVINE, D. D. The repeated acquisition of behavioral chains. Journal of the Experimental Analysis of Behavior, 1968, 11,651-660.

GOLdIAMOND, I. Perception, language, and conceptualization rules. In $B$. Kleinmuntz (Ed.), Problem solving: Research, method, and theory. New York: Wiley, 1966. Pp. 183-224.

HARLOW, H. F. The formation of learning sets. Psychological Review, 1949,56. $51-65$

SIDMAN, M. Tactics of scientific nesearch. New York: Basic Books, 1960.

THOMPSON, D. M. Repeated acquisition as a beh a vioral baseline. Psychonomic Science, 1970, 21, 156-157.

ZEIGLER, H. P. Learning-set formation in pigeons. Journal of Comparative \& Physiological Psychology, 1961, 54, 252-254.

\section{CURRENT LITERATURE ON ANIMAL CONDITIONING}

BLACK, M. \& SUBOSKI, M. D. (Queen's University, Kingston, Ontario, Canada). Incubation and ECS-produced gradients in one-trial and multitrial discriminated. avoidance conditioning in rats. Journal of Comparative and Physiological Psychology, 1971, 74, 325-330.

BRADLEY, R. M. (Nuffield Institute for Medical Research, University of Oxford, Headington, Oxford, England), \& MSTRETTA, C. $M$. Intravascular taste in rats as demonstrated by conditioned aversion to sodium saccharin. Journal of Comparative and Physiological Psychology, 1971, 75, 186-189.

CICALA, G. A. (University of Delaware, Newark, Del. 19711), Masterson, F. A., \& KUBITSKY, G. Role of initial response rate in avoidance learning by rats. Journal of Comparative and Physiological Psychology, 1971, 75, 226-230.

DeVIETTI, T. L. (Central Washington State College, Ellensburg, Wash. 98926), \& LARSON, R. C. ECS effects: Evidence supporting state-dependent learning in rats. Journal of Comparative and Physiological Psychology, 1971, 74, 407-415.

DUNCAN, P. M. (Department of Physiology and Biophysics, University of Washington, Seattle, Wash. 98105). Effect of temporary septal dysfunction on conditioning and performance of fear responses in rats. Journal of Comparative and
Physiological Psychology, 1971, 74, 340-348.

EICHELMAN, B. S., JR. (National Institute of Mental Health, Bethesda, Md. 20014). Effect of subcortical lesions on shock-induced aggression in the rat. Journal of Comparative and Physiological Psychology, 1971, 74, 331-339.

ISON, J. R. (University of Rochester, Rochester, N.Y. 14627), \& LEONARD, D. W. Effects of auditory stimuli on the amplitude of the nictitating membrane reflex of the rabbit (Oryctolagus cuniculus). Journal of Comparative and Physiological Psychology, 1971, 75, 157-164.

KETTLEWELL, N. M. (University of Montana, Missoula, Mont. 59801), \& PAPSDORF, J. D. A role for cutaneous afferents in classical conditioning in rabbits. Journal of Comparative and Physiological Psychology, 1971, 75, 239-247.

KRANE, R. V., \& ISON, J. R. (University of Rochester, Rochester, N.Y. 14627). Positive induction in differential instrumental conditioning: Effect of the interstimulus interval. Journal of Comparative and Physiological Psychology, 1971, 75, 129-135.

KREMER, E. F. \& KAMIN, L. J. (Princeton University, Princeton, N.J. 08540). The truly random control procedure: Associative or nonassociative effects in rats. Journal of Comparative and Physiological Psychology, 1971, 74, 203-210.
MARWINE, A. G., \& COLLIER, G. (Rutgers-The State University, New Brunswick, N.J. 08903). Instrumental and consummatory behavior as a function of rate of weight loss and weight maintenance schedule. Journal of Comparative and Physiological Psychology, 1971, 74, 441-447.

OLIVERIO, A. (Laboratorio di Psicobiologia e Psicofarmacologia, C.N.R. 1, via Reno 00198 Rome, Italy). Genetic variations and heritability in a measure of avoidance learning in mice. Journal of Comparative and Physiological Psychology, 1971, 74, 390-397.

POULOS, C. X., SHEAFOR, P. J., \& GORMEZANO, I. (University of Iowa, Iowa City, lowa 52240). Classical appetitive conditioning of the rabbit's (Oryctologus cuniculus) jaw-movement response with a single-alternation schedule. Journal of Comparative and Physiological Psychology, 1971, 75, 231-238.

RESCORLA, R. A. (Yale University, New Haven, Conn. 06510). Summation and retardation tests of latent inhibition. Journal of Comparative and Physiological Psychology, 1971, 75, 77-81.

ROHRBAUGH, M., BRENNAN, J. F., \& RICCIO, D. C. (Kent State University, Kent, Ohio 44240). Control of two-way shuttle avoidance in rats by auditory frequency and intensity. Journal of Comparative and Physiological Psychology, 1971, 75, 324-330. 